\title{
FROM CARING ABOUT SUSTAINABILITY TO DEVELOPING CARE-FUL ENGINEERS
}

\author{
Diane P. Michelfelder 1,3 , Sharon A. Jones ${ }^{2}$ \\ ${ }^{1}$ Macalester College, USA \\ 2 University of Portland, USA \\ 3 michelfelder@macalester.edu
}

\begin{abstract}
Engineering is commonly thought of as a problem-solving profession (e.g. Allenby, 2009; Zhou, 2012). Still, good problem-solving depends on good problem-framing, which typically means capturing both the technical and social aspects of the problem at hand. It can though be challenging for engineering students to capture both these aspects of a problem. Cech (2014) has pointed out that significant challenges still exist within engineering curricula with regard to "reading" technical problems with multiple layers of meaning. What can be done to better this state of affairs? Fortunately, sustainability issues have caught the attention of this generation of college students (Watson et. al., 2013). Building on the student enthusiasm associated with sustainability may be one way to foster student development regarding how to include ethical dimensions as an integral part of engineering framing and problem solving. We suggest that one option to achieve this is by teaching sustainability using an ethic of care framework that offers elements that more easily engage individuals in problem framing. This approach assumes that because engineering students "care" about sustainability as it applies to their disciplines, faculty can use an ethic of care framework to help students operationalize ethics as an integral component of the engineering decisionmaking process. By building on these initial lessons, students are better prepared to consider the sociotechnical dimensions of engineering problems. Our argument draws upon examples from the University of Portland that both demonstrate how students have a difficult time translating ethical theories to engineering problems, and show how the ethic of care approach can manifest itself naturally in the engineering curricula. We hope this paper serves to facilitate efforts to intentionally use sustainability issues to improve the teaching and learning of engineering ethics and further cultivate the T-shaped engineer.
\end{abstract}

\section{INTRODUCTION}

When in 2008 the National Academy of Engineering (NAE) announced its fourteen Grand Challenges for engineering and divided them across the four dimensions of sustainability, health, security, and the joy of well-being, it simultaneously acknowledged the primacy of those challenges connected with sustainability. "Foremost among the challenges are those that must be met to insure the future itself" (NAE, 2008). With regard to this emphasis, it bodes well that a significant percentage of engineering students are interested in sustainability, and those engineering students are particularly interested in sustainability topics that pertain to engineered systems (Watson et. al., 2013; UBC, 2009). More evidence of this interest can be found with the many student chapters of Engineers for a Sustainable World, Engineers without Borders, and Engineering World Health; three groups with a mission to allow students to apply their engineering knowledge to improve the sustainability of developing communities.

We suggest that if intentionally designed, the positive impacts from leveraging student interest in sustainability can go beyond helping to address sustainability-related challenges, to reach into the heart of how the activity of engineering is conventionally perceived. In particular, we propose that education in 
sustainable engineering lends itself well in helping future practitioners see that engineering design is not simply equivalent to technical problem-solving, but inherently involves internalizing social and ethical values as part of the problem-framing processes that lead to good solutions. Before engineering education in sustainability can have such an impact, however, the challenge faced by many engineering students of capturing both a problem's ethical and technical dimensions in the design process needs to be addressed. Because of this challenge, focusing on sustainability, even though sustainability is a normative concept, might not by itself be sufficient for developing student awareness of this inter-connectivity.

How can awareness of this inter-connectivity best be generated? In this paper, we respond to this question by suggesting that one option for developing this awareness is by approaching ethical-decision making through the lens of an ethics of care. We start by looking at an example at the University of Portland that illustrates the problem that engineering students have when connecting ethical theories to technical decision making. We then describe how an ethics of care can be used to direct student interest in sustainability to include the ethical context as an inherent part of framing an engineering problem which we illustrate with another example from the University of Portland. We conclude with lessons learned and suggestions for the next steps.

\section{2 (NOT) DRAWING CONNECTIONS}

All $A B E T$-accredited undergraduate engineering programs are required to have a culminating major design experience which students complete to demonstrate the knowledge and skills that they acquired over their education, and that they can incorporate appropriate engineering standards and multiple realistic constraints (ABET, 2013). At most schools, this culminating design experience is referred to as the senior capstone. At the University of Portland, all engineering major programs include a three-semester senior capstone experience with a one-credit introduction to the senior capstone in the spring semester of junior year known as EGR 300, along with the more traditional courses in fall ( 2 credits) and spring ( 3 credits) semesters of the senior year. The aim with EGR 300 is to help students not only select their project, but also to learn about the various professional issues that may affect successful completion of that project and, ultimately, projects in their future careers. One of these professional issues is engineering ethics.

The University of Portland is a Catholic university where all students complete the same core curriculum which includes a relatively heavy dose of theology and philosophy. Most undergraduate engineering students (as with each student on campus) will have completed Introduction to Philosophy, as well as Ethics (taught by faculty in the Philosophy department) prior to taking EGR 300. The sophomore-level ethics course provides an introduction to some of the major approaches in classical and contemporary moral philosophy emphasizing the ability to understand and concretely apply theories such as utilitarianism, deontological ethics, social contract theory, the ethics of care, natural law, and virtue theory while exploring the limits of relativism and absolutism.

In EGR 300, faculty use a small module in the course to briefly remind students of these lessons from their ethics course and how they apply to their discipline. This opportunity was also used to assess student understanding of professional and ethical responsibility as required by ABET. The assessment involved four performance criteria with a scoring scale of 4 (clear demonstration of superior attainment), 2 (adequate attainment), and 0 (poor attainment). The performance criteria are as follows:

- Performance criteria 1: Students recognize ethical issues, i.e., they can see the ethical implications of specific situations and choices.

- Performance criteria 2: Students can analyze and critically evaluate ethical dilemmas, have an understanding of competing values, and can scrutinize options for resolution.

- Performance criteria 3: Students can apply the engineering code of ethics for their discipline to a professional situation.

- Performance criteria 4: Students recognize that there may be no single ideal solution to ethically problematic situations. 
2.1 In Spring 2014, the assessment directed each student to provide an analysis of the assigned case study Henry's Daughters@ (NIEE 2010) which deals with various business ethics and technical ethics issues associated with the research and development of autonomous vehicles. Two and a half instructional sessions were used to remind students about ethics, draw the connection to engineering, and discuss the professional codes. In the first session, a philosophy professor presented a review of ethical theories to the entire cohort of students. In half of the second session, an engineering instructor led a discussion of the case study used for the ethics assessment. In the other half of the second session, a panel of practicing engineers discussed ethical situations in their own careers. In the final $1 / 2$ session, various engineering instructors discussed the code relevant to each major. The students' analyses of the case study were then assessed in regards to the four performance criteria listed above. In the assignment, students were required to choose two ethical issues to analyze from the many presented in the case study. They were provided with a template for the solution and the solution was graded using a defined rubric. The possible grades were $4,3,2,1$, or 0 , with 4,2 , and 0 equal to the scoring scale above. The student averages for the assignment are shown in the table below.

\begin{tabular}{|c|c|c|}
\hline Majors & \# Students & Average \\
\hline Civil Engineering & 42 & 2.74 \\
\hline Computer Science & 24 & 2.88 \\
\hline Electrical Engineering & 34 & 3.24 \\
\hline Mechanical Engineering & 54 & 3.02 \\
\hline Overall Average & $\mathbf{1 5 4}$ & $\mathbf{2 . 9 3}$ \\
\hline
\end{tabular}

Figure 1: Average scores for ethics assignment

While the results indicate that students attained the ABET outcome, they also disclosed several problems with how well students connected their sophomore ethics course with the engineering process. Note that while some students felt that the EGR 300 module was needed to supplement what they learned in the required ethics course, many others stated that they learned "all they needed" in the ethics course and EGR 300 was redundant. In the evaluation, students also noted that the case study was too simplistic and removed from what "real" engineers do. Despite the critique, the most difficult aspect of the written assessment for almost all students was developing an adequate range of alternative actions to address the two ethical situations that they identified in the case study. Even more relevant for this paper is the fact that few students selected any of the technical ethics issues to analyze i.e., the issues of social experimentation and risk/safety associated with this particular case study. Instead, they chose to focus on the business ethics issues such as favoritism, conflict of interest, and sexual harassment. While in part this result may be due to the video's poor portrayal of gender issues (Riley, 2013), it was clear that many students did not see the connection between what they learn in Ethics with the engineering process itself.

\section{DRAWING CONNECTIONS THROUGH SUSTAINABILITY EDUCATION AND THE ETHIC OF CARE}

How then can students in an engineering ethics class more readily see this connection? In this section, we discuss a possible path to developing this capacity. The path involves leveraging student concern for sustainability and using the ethic of care as a vehicle for helping students to frame a problem in which sustainability is at stake. As the next example from the University of Portland shows, it is in the problemframing stage that students can best learn to see the connection, so that the problem they would then go on to solve would already be regarded as a technical-ethical in character.

The lives of many of today's engineering students reflect a devotion to the cause of sustainability that runs both intellectually and emotionally deep. This devotion bears the characteristics of what philosopher Bernard Williams called a "commitment": a form of caring about something or someone that provides meaning for an individual's life, to which someone might point to in saying "this is what my life is about" (Williams, 1973). Because this commitment is part of the self-identity of these students, it makes sense to say that they care about sustainability rather than simply have an interest in it, as interests can be abandoned without any impact on self-identity. In his theory of education, Alfred North Whitehead proposed 
that the cultivation of learning begins with a stage of "romance," in which pupils are exposed to experiences that would captivate their interest and their emotion. (cf. Heywood, 2012). It could be said that with respect to sustainability, many students are already in the "romance" stage, prior to any deliberate intervention on a faculty member's part.

Given how many students already care about sustainability as part of their self-identity, we propose both to take it as a starting point for an engineering ethics course (or module), and to connect it to student learning about the particular theoretical approach to ethics known as the ethics of care. As the senior capstone project we will discuss in the next section will show, at least some students naturally gravitate toward an ethics of care approach, without naming it as such, when involved in a sustainable design project. Because of this natural gravitation, we believe leveraging students' interest in sustainability makes for a good entry point with respect to developing their mindset so that they naturally include ethical considerations as inherent to the engineering design process. Our work builds on prior attempts to draw connections between an ethics of care and engineering. In a pioneering paper from 1999, Pantazidou and Nair reflected on how the ethics of care could offer a general pedagogical framework for teaching engineering students the design process. In a more recent paper, Bielefeldt and Canney (2015) propose a framework that is in part based on an ethics of care in order to help understand how engineering students develop their own personal and professional responsibility. Jones, et. al. (2015) demonstrate how an ethics of care framework can be used to help engineering managers incorporate sustainability as part of the engineering process itself. We would be remiss if we did not mention Riley's paper (2013) that reminds us that there are instances where an ethics of care approach to engineering has unfortunately been distorted by others to be the more traditional "standard of care," or worse, to be a defensive reaction to the notion of care as minimizing the moral agency of men.

Before turning to our example, a description of some of the key elements of care ethics is in order. In general, care ethicists agree that the context in which a moral agent is located provides not only the starting point for ethical deliberation, but contains moral content that needs to be specifically taken into account as deliberation develops. This emphasis on context separates care ethics from other ethical theories, including deontological ethics and consequentialism. For deontological ethics, moral decision making involves the application of a principle of reason for which the context of decision-making acts simply as a trigger or starting-point. In consequentialism, the context of action holds more moral import in that it needs to be taken into account in making a moral decision, but primarily as "input" for a decision-making procedure also governed solely by reason. By contrast, within care ethics, context functions in a more concrete, determinative way. A caring moral agent would act in response to what he or she discovers are the needs of individuals within a particular context (see for example Noddings 1984). This implies that there is no "one-size-fits-all" solution to moral dilemmas that share similar characteristics; each must be approached and addressed on its own merits and not as an instantiation of a particular moral "problem."

The ethic of care also conceptualizes the moral agent differently from other ethical theories, including the theory of aspirational ethics developed by Bowen (2009) in recognition of the fact that today's engineers need to design responsibly for a future where the scale of the potential impacts of their work far exceeds that of the past (Bowen 2009, 11). Rather than thinking of the moral agent as a self-sufficient, independent individual, the approach care ethics takes is to see individuals as fundamentally social creatures whose existence is primarily structured by relationships with others. These relationships are characteristically ones involving reliance upon others, so that a caring person, as a moral agent, directs her care toward others who are in need. While a caring moral agent certainly uses reason in making judgments about how best to care for others, these judgments are also rooted in relational feelings and attitudes, including empathy and trust. In forging and cultivating relationships involving such feelings and attitudes--for example, professorstudent relationships, a skilled caring moral agent would overall be interested in the flourishing and wellbeing of those for which she cares. In many cases, this interest would mean that over time the caring relationship would dissolve, or be transformed into a different relationship in which caring could be given by both parties on a fairly equal basis, but with each party still recognizing their dependency upon some others, say for instance those within a larger professional community. 


\section{CONSIDERING THIS FRAMEWORK IN TERMS OF A SENIOR CAPSTONE PROJECT}

As mentioned earlier, at the University of Portland, the engineering senior capstone is organized across three courses. In the Introduction to capstone course, students first hear about the project choices and then organize themselves into teams to select a project. Sometimes the projects that are initially selected have to be switched by the faculty due to a variety of factors. For the 2014/15 academic year, this happened to one of the civil engineering senior teams. The original project that the student team selected focused on using solar disinfection to treat water collected in a rooftop rainwater system in the Portland metropolitan region. Faculty associated this project with the general theme of sustainable design. During the summer of 2014, when it became clear that faculty could not support that project, the team's faculty advisor secured another project that also involved water treatment and sustainability, albeit within a very different context. When contacted about the project change, the student team expressed interest in the project since it involved "sustainability" in terms of civil infrastructure and they were excited at the prospect of a "free" trip over fall break. The team included ZH who was to pursue a masters' degree in environmental engineering the following year and was double majoring in Spanish; KH who completed an environmental REU that summer; and $\mathrm{CH}$ who was also planning to pursue a masters' degree in environmental engineering. The faculty advisor added another student member to the team, MS, a dual US-Mexico citizen who travels to Mexico frequently and is fluent in Spanish.

The new project site was located in the municipality of "Antigua" Santa Catarina Ixtahuacan in the Sololá department of Guatemala and within the Sololá Catholic Diocese, a 3-hour drive from Guatemala City. The community includes approximately 150 homes and the project was sponsored by a non-governmental organization (NGO) of the Diocese of Spokane known as Family to Family. Project members were initially told-and this is important to keep in mind--that there was no other NGO providing support and that government resources were unavailable. In addition to the faculty advisor and the client, the student team was advised by two Portland engineers on a voluntary basis. Both Portland engineers had prior experience with developing community infrastructure as did the faculty advisor. At present, the community which includes five barrios is served by three gravity water system fed by mountain springs without treatment. The NGO reported that families get sick from drinking the water, however the extent of the problem was unclear. Initially, the student team and faculty assumed that the 2014-2015 project included tasks to:

- Assess the extent of the current and future problem in terms of drinking water quality, water usage needs in terms of quantity vs quality, and community/municipality/NGO assets \& capabilities, limitations, etc.

- Identify and evaluate the possible potable water treatment goals for this community using available local and global information.

- Identify several centralized (community) and decentralized (household) alternatives to solve the problem in terms of feasibility, desirability, and viability --- the three pillars of sustainability.

- Design and complete the necessary experimentation (on site in Guatemala) to determine appropriate system parameters for treatment.

- Prepare complete designs (specifications, drawings, etc.) for each treatment alternative that can be given to the community leaders to implement (avoiding language barriers etc.).

- Prepare a complete cost analysis and present a worth analysis for this project, as well as a thorough sustainability assessment using the Envision ${ }^{\mathrm{TM}}$ Sustainable Infrastructure Rating System.

- Evaluate the pros and cons (design, construction, and operation) of each alternative based on above, and provide a final recommendation for the community. Consider how to best present the recommendation to avoid language barriers etc.

- Provide an O\&M manual and any training materials (Spanish and English) needed for the project.

- Throughout the project, consult organizations that have been effective with similar projects.

The student team planned to visit the community over Fall Break to facilitate the partnership and collect the necessary information. Although two of the students spoke excellent Spanish, arrangements were made for an American contractor with detailed knowledge of the community over years of experience and fluent in both Spanish and the native language to accompany them and serve as translator. Prior to the visit, the team worked diligently on the first few tasks. They conducted controlled experiments of the effectiveness of several treatment methods, researched the local socio-economics of the area, read best practices 
literature regarding rural infrastructure development in similar contexts, and consulted with their advisors. They also developed a detailed water quality sampling plan for the site visit along with household, clinic, and community surveys. The advisors alerted the students to the potential for project changes once they visited the site and discussed several possible scenarios that could affect their progress in the country. That said, the entire team, students and advisors, assumed that the problem as framed was to design a water treatment system(s) appropriate to the community context. The team displayed excellent work ethic, organizational skills, and interpersonal effectiveness, and showed genuine interest in serving the community

So what happened during and after the visit? The student team was very successful in terms of data collection that included information about public health, water quality throughout the life cycle of the water infrastructure, visual assessment of the infrastructure, and interviews with clinicians, the local priest, members of the three water boards, and a cross section of households. The site visit and the collected data convinced the students that they needed to re-frame the problem so that they could solve what "really mattered" to the community itself and not the many other stakeholders who had influenced the initial project statement. The team concluded that the water sources and water storage were not significantly contaminated to justify investing in a community-scale treatment system. Further, the community itself did not want a treatment system, did not like the taste of chlorinated water, and already had several donated but unused filters lying around. Instead, the student team suspected that the biggest water quality problem for the community was the improper sanitation practices observed at the individual households, along with the absence of a financial system to pay for ongoing operation and maintenance of the infrastructure. As such, they convinced their advisors to re-frame the problem as one to develop/provide educational materials regarding water use, and to research/ recommend a financial system to manage the infrastructure.

In general, this outcome is not unusual in terms of discovering that the technical field data changes the original assumption; after all, data collection is an important part of the engineering process. However, the students paid attention to the socioeconomic and cultural aspects of the community, which led them to frame the problem differently, which in turn led to a new project scope oriented towards finance and education rather than the "best" water treatment design that they could develop. In other words, these "Tprofessionals" considered the socio-technical context for the problem that was presented to them as part of the framing process. And, this led to a much more nuanced view of what sustainable infrastructure requires --- namely that the community takes ownership. This case study presents an example of postnormal science (Funtowicz and Ravetz, 2003) where complex problems necessitate frameworks and extended peer communities that address the interrelated natural, technical, and social contexts along with their inherent uncertainties and values.

But, there's more. During the site visit, the student team contacted their advisors and noted that they were struggling with what they themselves described as an "ethical" situation. Based on many conversations with community members, the student team discovered the reason why the community could not get any financial support from other NGOs, or the local government. They were told that in 1998, Hurricane Mitch destroyed much of the community's infrastructure such that most of the community relocated to avoid similar disasters. However, some of the community stayed in an area (the team's project site) that is considered uninhabitable and at too high of a risk for external aid; in fact external aid could be seen as facilitating a high risk of disaster for these people. Although the students could not verify all of the information they heard, from their own observations they concluded that the topography and geology negatively affected the water system infrastructure due to steep grade, loose soil, and frequent small earthquakes.

The student team wrestled with the question of whether to provide technical help (and financial help as requested by the community) that may only alleviate the situation in the short term, and even worse, encourage the community to live in a high risk situation. This ethical reflection continued upon the students' return to campus and played a significant role in their project re-framing, with the students deciding that since the community was not going to relocate in the short term, they should focus the capstone project on the primary reason, education and finance, for the immediate public health issue rather than engaging in the elaborate, but irrelevant design of new and more permanent treatment alternatives. In other words, the student team concluded that the community needed them in the short term, and caring for a community in 
some situations means helping the community to become less dependent on the care that is being given. This ethical dilemma was integral to how the student team framed their engineering project. Note that the student team made this decision despite the uncertainty of how their grade in the course could be affected, given that the course emphasizes traditional "design" as part of the requirements.

\section{FUTURE CONNECTIONS TO BE EXPLORED}

Our analysis in this paper has primarily been directed toward addressing the difficulty of how best to get students to connect the dots between their learning in a normative ethical theory course and their learning in an engineering ethics class (or module). We have shown that an ethics of care approach has the advantage of offering elements that can more easily engage students in understanding that the activity of problem-framing in engineering has ethical dimensions. And, we have shown an example of how sustainable development, and in particular, meeting those to be "cared for," resulted in a senior capstone team using ethical and other societal aspects in problem framing.

This leads to the following question: How can this initial caring about the community and the socio-technical complexity of sustainable development be used to expand students' ability to apply post-normal science to the similarly complex problems that they will most definitely face in the $21^{\text {st }}$ century? We suggest that this expansion of a student's internalization of ethics can occur through a process of analogical reasoning where, to borrow a phrase from the philosopher Ludwig Wittgenstein, other engineering problems are seen to bear "family resemblances" to problems in sustainability. In addition, helping engineering students to develop skills of analogical reasoning could encourage them to move from caring about particular others with whom they have worked face to face e.g., in rural communities in the developing world, to others of different kinds. With regard to just who it is that can be cared for, Virginia Held $(1993,59)$ observes that "particular others can be actual children in need in distant countries, or the anticipated children of generations not even close to being born." For our perspectives discussed in this paper, this wide compass discloses the flexibility of care ethics and the potential for its use in a variety of engineering contexts. An engineering ethics course that starts with a module on sustainability in terms of an ethics of care and then uses "scaffolding" to increase students' capacity for recognizing the ethical dimensions may be one step towards developing an engineering mindset that inherently includes the broader context within which technical problems rest. To take this step is not to say that engineering ethics courses should concentrate on developing this particular approach alone. But, reflecting on what approach might be best to take with regard to framing a design problem involves being attentive to its particular nuances and detail. Here too the ethics we have been discussing can play a role in the formation of more "care-ful" engineers.

\section{Acknowledgements}

The four senior civil engineering majors at University of Portland who agreed to let us use this example, and the reviewer comments that connected us to related literature.

\section{References}

ABET. 2013. Criteria for Accrediting Engineering Programs, ABET, Baltimore, MD.

Allenby, B.R. 2009. The Challenge of Sustainable Engineering Education. Union College Symposium on Engineering and Liberal Education: Educating the Stewards of a Sustainable Future. Schenectady, NY: 5-6 June.

Bowen, W.R. 2009. Engineering Ethics: Outline of an Aspirational Approach. Dordrecht, NL: Springer Press.

Canney, N., A. Bielefeldt. 2015. A Framework for the Development of Social Responsibility in Engineers. International Journal of Engineering Education, 31(1B): 414-424.

Cech, E. A. 2014. Culture of Disengagement in Engineering Education? Science, Technology, and Human Values, 39(1): 42-72.

Funtowicz, S. and J. Ravetz. 2003. Port-normal Science. Internet Encyclopedia of Ecological Economics, International Society for Ecological Economics, February: 1-10. 
Held, V. 1993. Feminist Morality: Transforming Culture, Society, and Politics. Chicago, IL: The University of Chicago Press.

Heywood, J. 2012. Education at the Crossroads: Implications for Educational Policy Makers. 2012 Distinguished Lecture. American Society for Engineering Education. June 10-13, San Antonio, TX.

Jones, S. A., D. Michelfelder, and I. Nair. 2015. Engineering managers and sustainable systems: the need for and challenges of using an ethical framework for transformative leadership. Journal of Cleaner Production. DOI: 10.1016/j.jclepro.2015.02.009

National Academy of Engineering. 2008. Grand Challenges for Engineering. http://www.engineeringchallenges.org/cms/8996.aspx.

National Institute for Engineering Ethics, 2010. Henry’s Daughters @ 2010, Lubbock, TX.

Noddings, N. 1984. Caring: A Feminine Approach to Ethics and Moral Education. Berkeley, CA: University of California Press.

Pantazidou, M. and I. Nair. 1999. Ethic of care: Guiding principles for engineering teaching and practice. Journal of Engineering Education, 88(2): 205-212.

Riley, D. 2013. Hidden in Plain View: Feminists Doing Engineering Ethics, Engineers Doing Feminist Ethics. Journal of Science and Engineering Ethics, 19: 189-206.

University of British Columbia (UBC). 2009. Sustainability education at UBC: A student perspective, Campus Sustainability Office, Kelowna, BC, Canada.

Watson, M.K., C. Noyes, and M. Rodgers, 2013. Student Perceptions of Sustainability Education in Civil and Environmental Engineering at Georgia Institute of Technology. Journal of Professional Issues and Practice, July: 235-243.

Williams, B. 1973. A Critique of Utilitarianism. In J.J.C. Smart and B. Williams, Utilitarianism: For and Against. Cambridge: Cambridge University Press, 82-117.

Zhou, C. 2012. Fostering creative engineers: a key to face the complexity of engineering practice. European Journal of Engineering Education, 37(4): 343-353. 